J. Clin. Chem. Clin. Biochem.

Vol. 26, 1988, pp. 25-28

(C) 1988 Walter de Gruyter \& Co.

Berlin - New York

\title{
Improvements in the Simultaneous Determination of Calcidiol and Calcitriol in Human Serum or Plasma
}

\author{
By M. J. Jongen, S. Kuiper, W. J. F. van der Vijgh, P. Lips and J. C. Netelenbos \\ Research Laboratory, Department of Internal Medicine, Academisch Ziekenhuis Vrije Universiteit, \\ Amsterdam, The Netherlands
}

(Received May 12/November 11, 1987)

\begin{abstract}
Summary: Technical improvements have been applied to reduce the time required for the determination of calcidiol and calcitriol in serum or plasma. The modifications include the use of Sep-Pak C18 cartridges for the extraction of calciol metabolites from serum instead of a classical liquid/liquid extraction, a considerable shortening of the HPLC purification time compared with our previously described method, and the application of HPLC with UV detection at $254 \mathrm{~nm}$ of calcidiol as an alternative to the usual competitive protein binding methods. In none of the 199 samples where calcidiol was determined by HPLC did we observe a detectable peak of ercalcidiol. Quantitation of calcidiol by HPLC and competitive protein binding assay was compared in 5 series of assays. The correlation between the two methods was 0.99 . The average slope of the linear regression line when the HPLC values were plotted versus the competitive protein binding values was 1.14. The average intercept was $0.19 \mathrm{nmol} / \mathrm{l}$. The mean within-run coefficient of variation for calcidiol in these series was $5 \%$ for the competitive protein binding method, and $4 \%$ for the HPLC method. Between-run coefficients of variation were $6 \%$ and $12 \%$ for the competitive protein binding and for the HPLC method, respectively. Within-run and between-run coefficients of variation for calcitriol were $6 \%$ and $15 \%$, respectively.
\end{abstract}

\section{Introduction}

Methods for the determination of calciol metabolites in plasma or serum have always been laborious due to the necessity for extensive prepurification before quantitation $(1,2)$. Determination of calcidiol by HPLC with UV detection at $254 \mathrm{~nm}$ is possible only after at least two chromatographic procedures $(3-5)$, or after one chromatographic prepurification and conversion to a (5E)-(10S)-10,19-dihydrocalciol derivative (6). Quantitation of calcidiobl by HPLC enables the separate determination of ercalcidiol and calcidiol. The competitive protein binding method, however, gives only the sum of both compounds. Previously, we described a procedure for the simultaneous determination of calcidiol, calcitriol and (24R)-hydroxycalcidiol (7). For large clinical research projects, where hundreds of samples have to be analysed, and for routine clinical use, it was desirable to develop a less time consuming method, especially with respect to the HPLC procedure used for the purification of the sample extracts. Here we describe the technical details of the modifications which resulted in a substantial reduction of HPLC time required for prepurification of the sample extracts. In addition, we describe a modified sample extraction with Sep-Pak C18 cartridges and a comparison of the quantitation of calcidiol by HPLC with UV detection at $254 \mathrm{~nm}$ and competitive protein binding assay.

\section{Materials and Methods}

Materials

Nonradioactive calcidiol and calcitriol were obtained from $\mathrm{Du}$ phar BV, Weesp, The Netherlands and Hoffmann-LaRoche, Basle, Switzerland, respectively. [27-methyl- $\left.{ }^{3} \mathrm{H}\right]$ calcidiol (spec. act. $185-555 \mathrm{GBq} / \mathrm{mmol}$ ) and $\left[23,24(\mathrm{n}){ }^{3} \mathrm{H}\right]$ calcitriol (spec. act. 2.6-4.1 TBq/mmol) were purchased from Amersham Nederland BV, Utrecht, The Netherlands. Calciol metabolites were stored in absolute ethanol at $-20^{\circ} \mathrm{C}$. All solvents were of commercially available analytical grade and were uscd without further purification. Radioactivity in aqueous samples was 
counted in $10 \mathrm{ml}$ of Instagel (Baker Chemicals, Deventer, The Netherlands). Radioactivity in organic solvents was measured in $5 \mathrm{ml}$ of Permafluor III (Packard Instruments Benelux SA, Brussels, Belgium) diluted ten-fold with toluene. Nucleosil packing materials for HPLC columns were from Macherey \& Nagel, Düren, FRG.

\section{Apparatus}

The Altex HPLC system (Altex, Berkely, CA 94710) was essentially the same as described before (7). A Rheodyne Model $7040 \mathrm{~A}$ low dead volume valve fitted with a Model 7163 solenoid valve (Rheodyne Inc, Ciotati, CA 94928) was added to the system in order to enable reversal of the flow through the HPLC column. Fractions were collected with an LKB Model Ultrorac 7000 fraction collector (LKB, Bromma, Sweden). A Sep-Pak cartridge rack (Millipore/Waters Ass., Etten Leur, The Netherlands) was used for the processing of sample extracts with Sep-Pak C18 cartridges. Radioactivity was measured in a Philips Model PW 4700 liquid scintillation counter (Philips, Almelo, The Netherlands).

\section{Sample preparation}

To $4 \mathrm{ml}$ of plasma or serum were added approximately $83 \mathrm{~Bq}$ each of tritiated calcidiol and calcitriol. After equilibration at ambient temperature for 30 minutes, one volume of acetonitrile was added to the sample. After vortex-mixing the denatured proteins were pelleted by centrifugation. Subsequently, 0.6 volume of water was added to the supernatant, which was then applied to a Sep-Pak C18 cartridge. The cartridge was washed with $5 \mathrm{ml}$ of methanol/water $(60+40$ by vol). Calciol metabolites were eluted with $2.5 \mathrm{ml}$ ethanol, evaporated under a stream of nitrogen and redissolved in $210 \mu \mathrm{l}$ of hexane/isopropanol $(90+10$ by vol) for HPLC. A Nucleosil 10-NO2 column $(16 \times 0.46 \mathrm{~cm})$ was used for prepurification by HPLC. Gradient elution was performed with two solvents, $\mathrm{A}$ and $\mathrm{B}$. Solvent $\mathrm{A}$ consisted of a mixture of $n$-hexane, isopropanol and water ( 2800 $+1200+42$ by vol). Solvent B was $n$-hexane. The flow was $4 \mathrm{ml}$ per minute. From $0-5$ minutes $13 \% \mathrm{~A}$ was used to elute calcidiol. From 5.0-5.5 minutes the percentage of $A$ was increased to $31 \%$. At 10 minutes the flow through the column was reversed and the percentage of $\mathrm{A}$ increased to $100 \%$. After 9 minutes of backflushing the percentage of $\mathrm{A}$ was restored to $13 \%$ for reequilibration of the column for the next injection. After 11 minutes of backflushing the flow direction was switched back to normal. Total run time for each sample was 25 minutes. Calcidiol and calcitriol were collected from 2.02.6 minutes and 9.0-10.0 minutes, respectively. After evaporation under nitrogen the fractions containing calcidiol and calcitriol were redissolved in 2000 and $175 \mu \mathrm{l}$, respectively, for assessment of analytical recovery and final quantitation. In 5 series of assays $(n=199)$, part of the calcidiol fraction was used for the simultaneous quantitation of calcidiol by HPLC with UV detection at $254 \mathrm{~nm}$ and competitive protein binding assay, in order to directly compare these two methods of quantitation. Within-run and between-run coefficients of variation were determined by the inclusion of 4 control samples in each series of assays.

\section{Quantitation}

The binding assays for calcidiol and calcitriol were carried out as described before (7). For quantitation of calcidiol, $800 \mu \mathrm{I}$ were taken for the determination of analytical recovery, and two $50 \mu \mathrm{l}$ aliquots for competitive protein binding assay. The remainder, approximately $1100 \mu$, was used for HPLC quantitation. After evaporation under nitrogen the residue was taken up in $80 \mu \mathrm{l}$ of methanol/water $(88+12$ by vol). Fifty $\mu$ l were injected onto a Nucleosil $5-\mathrm{C} 18$ column $(25 \times 0.46 \mathrm{~cm})$. Methanol/water $(88+12$ by vol) was used as the eluent at a flow rate of $1.5 \mathrm{ml} / \mathrm{min}$. The calcidiol fraction was collected $(10-$ 13 minutes) and radioactivity was determined in $5 \mathrm{ml}$ of Permafluor III after evaporation of the solvent. The sample concentration was calculated from peak height measurement and the determined analytical recovery. Peak height was calibrated each day by repeated injection of $30 \mathrm{ng}$ of authentic calcidiol in $50 \mu \mathrm{l}$ of solvent. A standard curve for calcidiol was constructed in the range of 12 to $120 \mathrm{ng}$ of calcidiol.

\section{Results}

Analytical recoveries for calcidiol and calcitriol after Sep-Pak C18 and straight phase HPLC purification were $72 \%$ and $65 \%(n=199)$, respectively. The retention times of calcidiol and calcitriol on the Nucleosil 10-NO2 column were 2.3 and 9.5 minutes respectively. Ercalcidiol and calcidiol are not separated on this column (7). The retention times were stable for several months, which allowed reliable automatic processing of several hundreds of sample extracts with one column. The use of Sep-Pak C18 cartridges resulted in extracts which, after chromatography on the Nucleosil 10-NO2 column, were clean enough to enable HPLC quantitation of calcidiol on the Nucleosil 5-C18 column. The peak height for calcidiol was linear in the range from 12 to $120 \mathrm{ng}$ (coefficient of correlation $r=0.999$ ). Figure 1 shows typical chromatograms of a standard solution and two human serum extracts in the normal and low concentration range
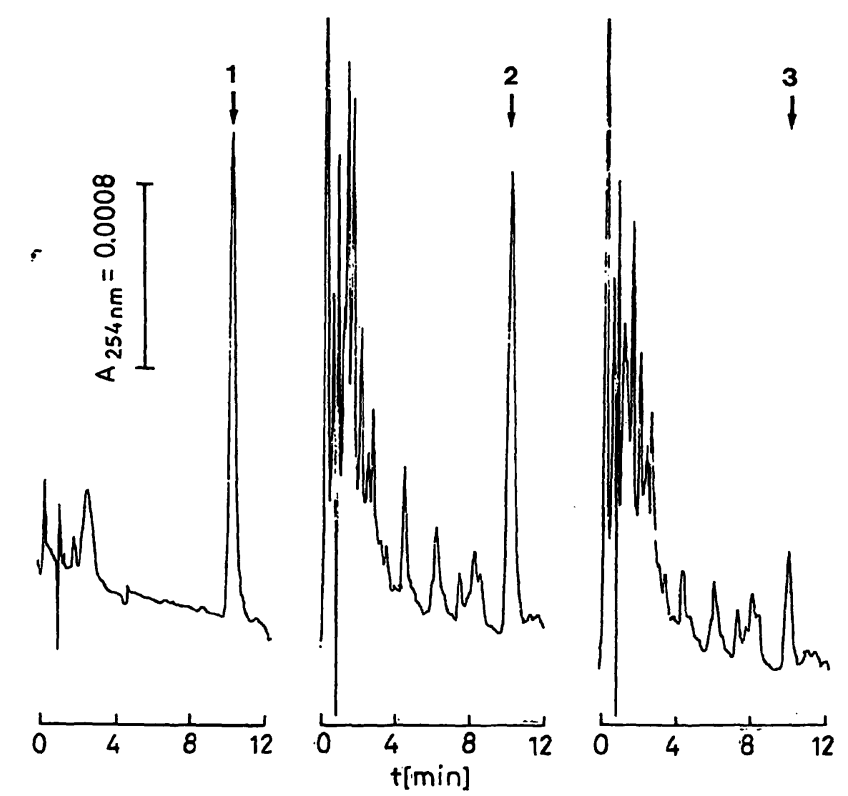

Fig. 1. Representative UV tracings at $254 \mathrm{~nm}$ on a Nucleosil 5 -C18 column $(25 \times 4.6 \mathrm{~mm}$; methanol/water $(88+12$ by vol) at a flow rate of $1.5 \mathrm{ml} / \mathrm{min}$ ) of 1) $30 \mathrm{ng}(0.075 \mathrm{nmol})$ of authentic calcidiol, 2) a plasma extract of a sample containing $85 \mathrm{nmol} / \mathrm{l}$ of calcidiol after Sep-Pak C18 and HPLC prepurification, and

3) plasma extract of a sample containing $27 \mathrm{nmol} / \mathrm{l}$ of calcidiol after Sep-Pak C18 and HPEC prepurification. $(10 \mathrm{nmol} / \mathrm{l}$ equals $4 \mu \mathrm{g} / \mathrm{l}$.) 
after Sep-Pak C18 and HPLC prepurification. There was a good correlation between the competitive protein binding assay and the HPLC method for the measurement of calcidiol ( $\mathrm{r}: 0.987 \pm 0.004 ; \mathrm{n}=5$ series of assays). The average slope of the regression line when HPLC values were plotted versus competitive protein binding values was 1.14 , with an average intercept of $0.19 \mathrm{nmol} / \mathrm{l}$. The mean within-run coefficient of variation for calcidiol was $5 \%$ for the binding assay and $4 \%$ for the HPLC method. Betweenrun coefficient of variation for calcidiol were $6 \%$ and $12 \%$ for the binding assay and the HPLC method, respectively. Within-run and between-run coefficients of variation for calcitriol in these 5 series were $6 \%$ and $15 \%$, respectively. The coefficients of variation were determined at concentrations of approximately $50 \mathrm{nmol} / \mathrm{l}$ and $100 \mathrm{pmol} / \mathrm{l}$ for calcidiol and calcitriol, respectively.

\section{Discussion}

At first we tested a previously described procedure for the purification of calciol metabolites from plasma (8). This method however, used only $2 \mathrm{ml}$ of serum. In our case, with sample volumes of $4 \mathrm{ml}$, substantial amounts of radioactive spike were lost with the supernatant of the sample extracts and during the washing procedure. The procedure was therefore modified as described. Addition of 0.6 volume of water $(2.5 \mathrm{ml}$ for a sample volume of $4 \mathrm{ml}$ ) to the supernatant prevented approximately $20 \%$ loss of radioactivity. Washing with methanol/water $(60+40$ by vol) instead of methanol/water $(70+30$ by vol) improved recovery of radioactivity by a further $10 \%$. Most of these losses were probably calcitriol because this metabolite elutes first from the Sep-Pak C18 cartridge. Elution with $2.5 \mathrm{ml}$ ethanol resulted in complete recovery of calcidiol and calcitriol from the cartridge. The described HPLC gradient resulted in a sufficient and fast isolation of calcidiol and calcitriol. To test for the accumulation on the HPLC column of substances interfering with the binding assays (in the absence of a back flush procedure), we analysed ten control sera in one series omitting the back-flush procedure and using only one Sep-Pak C18 cartridge. No change in assay results was observed. However, to exclude all possible interferences in the calcitriol binding assay (9) during routine analysis of large numbers of samples from patients with a wide variety of metabolic disorders, we decided to maintain a ten minute back flush procedure for routine purification. The total HPLC run-time of 25 minutes allowed the processing of 35-40 samples overnight. Since this is close to the maximal number of samples that can be handled in the binding assays, it was not necessary to reduce the HPLC time further. The use of Sep-Pak C18 cartridges and the Nucleosil 10-NO2 column for prepurification enabled HPLC quantitation of calcidiol without interference by endogenous UV-absorbing contaminants. When only calcidiol concentrations have to be determined or when information is required about both calcidiol and ercalcidiol, the HPLC method can be a valuable alternative to the competitive protein binding method. The method differs from the binding assay in that calcidiol and ercalcidiol are separated in the described reversed phase system (8). The binding assay measures the sum of calcidiol and ercalcidiol. For clinical use the sum of calcidiol and ercalcidiol is probably the best estimate of a person's status. Significant amounts of ercalciol metabolites, however, are usually not found in the Netherlands and in Germany (9). In samples from 199 subjects, we found no detectable quantity of ercalcidiol. This is in contrast to the situation in the USA, Canada and England, where a substantial proportion of the samples contain ercalciol metabolites $(3,8,10)$. Only in cases of supplementation with ercalciol can one expect a large contribution of ercalcidiol. Although ercalcidiol concentrations can be estimated by assuming the same analytical recovery for ercalcidiol and calcidiol, we did not further evaluate the determination of ercalcidiol, because it is only very seldom present in samples in the Netherlands. This was confirmed by the high correlation between the sum of calcidiol and ercalcidiol concentrations, as determined by the competitive protein binding method, and the HPLC method measuring only calcidiol.

\section{References}

1. Seamark, D. A., Trafford, D. J. H. \& Makin, H. L. J. (1981) J: Steroid Biochem. 14, 111-123.

2. Jongen, M. J. M., Van Ginkel, F. C., Van der Vijgh, W. J. F., Kuiper, S. \& Netelenbos, J. C. (1984) Clin. Chem. 30, $399-403$.

3. Jones, G. (1978) Clin. Chem. 24, 287-298.
4. Bouillon, R., Van Herck, E., Jans, I., Tan, B. K., Van Baelen, H. \& De Moor, P. (1984) Clin. Chem. 30.1731 1736.

5. Kao, P. C. \& Heser, D. W. (1984) Clin. Chem. 30, 56-61.

6. Turnbull, H., Trafford, D. J. H. \& Makin, H. L. J. (19S2) Clin. Chim. Acta 120, 65-76. 
7. Jongen, M. J. M., Van der Vijgh, W. J. F., Willems, H. J. J., Netelenbos, J. C. \& Lips, P. (1981) Clin. Chem. 27, 1757-1760.

8. Fraher, L. J., Adami, S., Clemens, T. L., Jones, G. \& O'Riordan, J. L. H. (1983) Clin. Endocrinol. 18, 151-165.
9. Mayer, E. \& Schmidt-Gayk, H. (1984) Clin. Chem. 30, 1199-1204.

10. Reinhardt, T. A., Horst, R. L., Orf, J. W. \& Hollis, B. W. (1984) J. Clin. Endocrinol. Metab. 58, $91-98$.

Dr. W. J. F. van der Vijgh

Research Laboratory

Dept. of Internal Medicine

Academisch Ziekenhuis

Vrije Universiteit

Post Box 7057

NL-1007 MB Amsterdam 